\title{
Particle Formation in ab Initio RAFT Mediated Emulsion Polymerization Systems
}

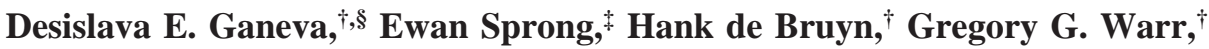 \\ Christopher H. Such, ${ }^{\ddagger}$ and Brian S. Hawkett ${ }^{*}, \dagger$
}

Key Centre for Polymer Colloids, Chemistry F11, University of Sydney, NSW 2006, and Dulux

Australia, McNaughton Road, Clayton, Victoria 3168, Australia

Received February 19, 2007; Revised Manuscript Received June 12, 2007

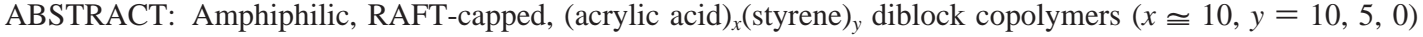
were synthesized and used as stabilizers in emulsion polymerization. Above the critical micelle concentration $(\mathrm{cmc})$ of the diblocks and under appropriate reaction conditions micelles of the more hydrophobic diblocks were sufficiently nonlabile to be nucleated and act as seed particles for latex particle formation. The key parameters which allow control over the system are diblock hydrophobicity and initiator concentration. A homogeneous nucleation mechanism is most likely to operate below the $\mathrm{cmc}$ of the diblocks.
\end{abstract}

\section{Introduction}

Reversible addition fragmentation chain transfer (RAFT) is a controlled radical polymerization technique, which makes possible the synthesis of a variety of polymer architectures such as blocks, stars, and brushes. It also has advantages over other controlled radical polymerization techniques due to its compatibility with a wide range of monomers, functional groups and experimental conditions. ${ }^{1}$ Until recently the application of RAFT polymerization to emulsion systems has been limited, mainly due to problems with transportation of the fairly water-insoluble RAFT agent into the latex particles. Reported problems associated with the direct application of the RAFT process in ab initio emulsion polymerization included: poor colloidal stability, loss of molecular weight control, phase separation into a RAFTrich and a polymer rich phase, slow polymerization rates, ${ }^{2}$ and broad molecular weight distribution. ${ }^{3}$ A method developed by Ferguson et al. ${ }^{4,5}$ allows these problems to be circumvented and stable latexes to be obtained under RAFT control. The process involves the formation of amphiphilic RAFT-capped, acrylic acid (AA) and styrene (Sty) block copolymers, which are then used as stabilizers in emulsion polymerization. Further polymerization of these amphiphilic diblocks generates the final latex particles. In this surfactant free emulsion process the amphiphilic RAFT-capped diblocks are not merely stabilizers but grow further to become an inseparable part of the latex particle.

In the previously proposed mechanism for particle formation (see Scheme 1) some of the micelles of the amphiphilic RAFTcapped diblocks are entered by $z$-meric radicals (surface-active water-soluble radicals resulting from the reaction of primary initiator radicals and monomer in the aqueous phase) and grow to become particles. ${ }^{6,7}$ As the particles grow, RAFT-capped diblocks from unentered micelles migrate through the water phase to stabilize the newly formed surface area and then propagate until they become too hydrophobic to desorb. The mechanism is based on the assumption that the surface active RAFT-capped $\mathrm{AA}_{x} \mathrm{Sty}_{y}$ diblocks $(x=5,10 ; y=5,10)$ are labile

\footnotetext{
* Corresponding author. E-mail: b.hawkett@chem.usyd.edu.au. Telephone: 61293516973 (work). Fax: 61293518651.

Key Centre for Polymer Colloids, Chemistry F11, University of Sydney.

Dulux Australia.

\&E-mail: desi.ganeva@uwa.edu.au.
}

(similar to low molecular weight surfactants) and undergo rapid exchange between micelles during the particle formation period. This is contrary to our expectations that RAFT-capped diblock exchange between the micelles should be on a much slower time scale than that of low molecular weight surfactants. The time scale of exchange in amphiphilic block copolymers is governed by the nature of blocks, their molecular weight, and overall hydrophobicity, and often stretches over several hours or even days. ${ }^{8}$ This has allowed, in some instances, a limiting case to be reached in which micelles act as seed for particle formation. ${ }^{9}$ Similar results were reported for hydrophobic poly(acrylic acid)-block-polystyrene, AA $\mathrm{Sty}_{y}$ (50-300AA, 1530Sty), diblocks used as stabilizers for emulsion polymerization of styrene. ${ }^{10,11}$ It was shown that the lability of $\mathrm{AA}_{x} \mathrm{Sty}_{y}$ diblocks is directly related to their overall hydrophobicity, i.e., the mol $\%$ of AA in their structure and that diblocks with as much as $75 \mathrm{~mol} \%$ AA do not exchange on the time scale of nucleation. Furthermore, the final number of latex particles in emulsion polymerization $N_{\mathrm{p}}$ was related to the mobility of the $\mathrm{AA}_{x} \mathrm{Sty}_{y}$ diblocks via the exponent $\alpha$ in Smith and Ewart's power law. ${ }^{12}$ The law, which relates $N_{\mathrm{p}}$ to the amount of stabilizer used $-N_{\mathrm{p}}$ $\sim$ [stabilizer $^{\alpha}{ }^{\alpha}$ is based on the assumption that particle formation stops when particle surface area is large enough to adsorb all surfactant in a saturated monolayer and that surfactants (due to their high mobility) are immediately available to stabilize newly formed interfaces. A value of 0.6 is typical for the exponent $\alpha$ of low molecular weight surfactants in the emulsion polymerization of Sty. ${ }^{13}$ In the work of Burguière et al. ${ }^{10,11}$ it was shown that relatively hydrophilic diblocks, containing between 75 and 94 mol \% AA were labile and behaved similarly to low molecular weight surfactants giving values of $\alpha$ between 0.4 and 0.6. More hydrophobic diblocks containing less than $75 \mathrm{~mol} \%$ AA gave $\alpha$ values close to 1 , indicating the limit of no diblock exchange between assemblies on the time scale of nucleation where each micelle is a seed for a latex particle.

It is unlikely that the high mobility reported by Ferguson et al. ${ }^{5}$ for the low molecular weight $(1647 \mathrm{~g} / \mathrm{mol})$, hydrophobic ( $\sim 50 \mathrm{~mol} \% \mathrm{AA})$, RAFT-capped $\mathrm{AA}_{x} \mathrm{Sty}_{y}$ diblocks is due to their low MW. A more likely reason for their lability might be that the diblocks were used in emulsion polymerization without prior removal of dioxane (the organic solvent used for their 
Scheme 1. Proposed Mechanism for Particle Formation in Emulsion Systems under Raft Control

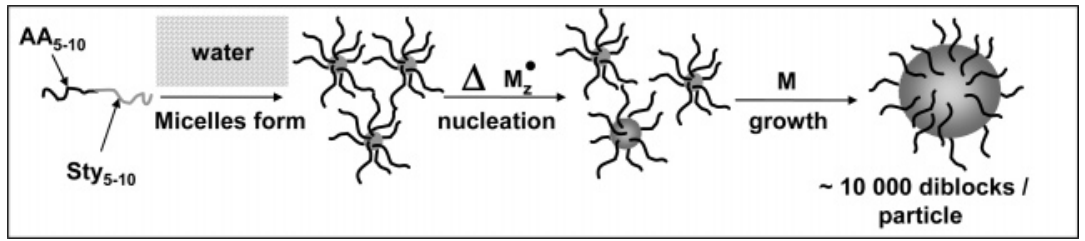

synthesis). Despite being a minor component in the final latex, the presence of a cosolvent (dioxane) would have a significant effect on the lability of RAFT-capped diblocks and thereby influence in the final particle size distribution. ${ }^{14}$

In this work we have investigated $\mathrm{AA}_{x} \mathrm{Sty}_{y}$ RAFT-capped diblocks with different hydrophobicity $(x \cong 10 ; y=10,5,0)$ and demonstrated that they can self-assemble to act as seed in emulsion polymerization. The length of the hydrophilic block is kept constant at $\sim 10$ AA units since reduction in the length of the hydrophilic tail could compromise latex stability. Despite their low molecular weight, short $\mathrm{AA}_{10} \mathrm{Sty}_{10-0}$ RAFT-capped diblocks have an advantage over other diblock copolymer stabilizers in that they extend the length of their hydrophobic block during the polymerization reaction and become part of the latex particle. Moreover, such micelles only need to be stable on the time scale of particle nucleation in order to act as seed particles in emulsion polymerization. The low molecular weight of the diblocks and their overall lability further aids their solubilization in water prior to the polymerization reaction.

\section{Experimental Section}

Materials. Acrylic acid (AA) and 1,4-dioxane (both Aldrich) were purified by distillation under reduced pressure. Styrene (Sty) and butyl acrylate (BA) (Aldrich) had the inhibitor removed by passing through an inhibitor removal column (Aldrich). 4,4'-Azobis(4-cyanopentanoic acid), V501 (Wako), deuterated styrene (Sty$\left.d_{8}\right)$ (Aldrich), sodium hydroxide $(\mathrm{NaOH})$, methanol, and pyrene (Aldrich) were used as received. RAFT agents $-2-\{[$ (butylsulfanyl)carbonothioyl]sulfanyl $\}$ propanoic acid (RAFT-C4) and 2-\{[(dodecylsulfanyl)carbonothioyl]sulfanyl \} propanoic acid (RAFT-C12)were prepared as previously described. ${ }^{5}$ Milli RO water was used in the synthesis of all latexes and for the preparation of micellar solutions.

Particle Size Analysis. Latex particle size was measured by HDC (hydrodynamic chromatography) using a Varian/Polymer Laboratories particle size distribution analyzer (PL-PSDA). The system was calibrated using monodisperse polystyrene latex standards with very narrow particle size distribution (Dow). The particles were detected after elution from the HDC column by a UV detector operating at $254 \mathrm{~nm}$. The eluent was a solution of proprietary surface active agents in water.

The average micelle diameter for diluted RAFT-capped diblock solutions was measured by dynamic light scattering (DLS) at $25^{\circ} \mathrm{C}$ and a $90^{\circ}$ angle using a Brookhaven BI-200 SM goniometer. The instrument, equipped with a $35 \mathrm{~mW} \mathrm{He} / \mathrm{Ne}$ laser operates at $633 \mathrm{~nm}$. It is noted that with both techniques a hydrodynamic diameter is measured, which includes the polystyrene core, the stabilizing oligo-AA shell and any structured water accommodated within the shell. To obtain a true particle diameter, it is necessary to subtract the thickness of the solvated shell around the particle. This was measured by SANS as described below. The particle size was converted to number of particles $N_{\mathrm{p}}$ per liter using eq 1 :

$$
N_{\mathrm{p}}=\frac{6 \times \text { total mass polymer }}{\pi d_{v}^{3} d_{\mathrm{p}}}
$$

where $d_{v}$ is the volume average particle diameter (in $\mathrm{cm}$ ) and $d_{\mathrm{p}}$ is the density of polystyrene, pSty $\left(d_{\mathrm{p}}=1.045 \mathrm{~g} / \mathrm{cm}^{3}\right)$.
Electrospray mass spectrometer analysis was done on a Finnigan LCQ MS detector with Finnigan LCQ Data Processing using Instrument Control Software. $20 \mu \mathrm{L}$ of solution $(10 \mu \mathrm{g}$ of sample dissolved in $10 \mathrm{~mL}$ of methanol) were fed into the electrospray ionization unit at $0.5 \mathrm{~mL} \cdot \mathrm{min}^{-1}$. The electrospray capillary voltage was $4.5 \mathrm{kV}$, the sheath flow rate was set to 50 $\mathrm{mL} / \mathrm{min}$, and the temperature of the heated capillary was $300{ }^{\circ} \mathrm{C}$.

Fluorescence Measurements. A stock solution of pyrenesaturated water was prepared by mixing a small amount pyrene with $250 \mathrm{~mL}$ of water and stirring the solution at $40{ }^{\circ} \mathrm{C}$ for 3 days. The solution was allowed to cool down to room temperature and then filtered through a $0.45 \mu \mathrm{m}$ Millipore filter. The saturated pyrene solution was then used to prepare pyrene/water/RAFT-capped diblock solutions with varying diblock concentrations. Emission intensities of the solutions were measured with a Varian Cary Eclipse Fluorescence spectrophotometer. The excitation wavelength was $340 \mathrm{~nm}$ and the emission bandwidth 2.5 or $5 \mathrm{~nm}$.

Surface tension measurements were carried out on a Sigma 70 Tensiometer. For these measurements, known quantities of a concentrated solution of RAFT-capped diblock in water were added to a known volume of water using a Metrohm, motor driven piston burette 665 Dosimat. The solution was stirred for $30 \mathrm{~min}$ after each addition and the surface tension was measured using a Du-Nouy ring.

Small-angle neutron scattering experiments (SANS) were performed on the NG7 $30 \mathrm{~m}$ SANS instrument at the NIST Centre for Neutron Research in Gaithersburg, MD. ${ }^{15}$ Sample scattering was corrected for background and empty cell scattering, and individual detector pixel sensitivity. The corrected data was circularly averaged and placed on an absolute scale using standard samples and software supplied by NIST. ${ }^{16}$

Size exclusion chromatography (SEC) measurements were performed on a Shimadzu system fitted with series of Waters columns (HR4, HR3, and HR2) and a DRI detector. Polymer Laboratories Cirrus Software was used with all molecular weights being relative to polystyrene standards and converted using "Universal Calibration" 17 and the following Mark-Houwink parameters: ${ }^{18}$ Sty, $K=11.4 \times 10^{-5} \mathrm{dLg}^{-1}, a=0.716$; BA, $K=12.2$ $\mathrm{dLg}^{-1}, a=0.70$. THF mixed with $5 \mathrm{wt} \%$ acetic acid was used as eluent to block carboxylic acid interactions due to the presence of a short acrylic acid moiety at the end of each chain.

Synthesis of Amphiphilic RAFT-Capped Mono- and Diblocks. The RAFT agents (RAFT-C4 and RAFT-C12) were reacted with AA in dioxane to give a hydrophilic AA-RAFT with an average of 10 AA units. In the case of RAFT-C12, the monoblock macroRAFT agent has an amphiphilic character owing to the long dodecyl tail in the RAFT structure. The products were characterized by electrospray mass spectrometry to confirm the relative abundance of AA-RAFT $x$-mers. Styrene was then added to the mixture and reacted for $5 \mathrm{~h}$ or overnight depending on the desired length of the hydrophobic Sty block (5 or 10 units). The structures of the synthesized amphiphilic RAFT agents are shown in Figure 1.

For a typical reaction procedure, $2.0 \mathrm{~g}\left(8.39 \times 10^{-3} \mathrm{~mol}\right)$ of RAFT-C4, $0.118 \mathrm{~g}\left(4.19 \times 10^{-4} \mathrm{~mol}\right)$ of V501, $6.046 \mathrm{~g}(8.39 \times$ $10^{-2} \mathrm{~mol}$ ) of AA, and $20 \mathrm{~g}$ of dioxane were mixed in a roundbottom flask. The mixture was stirred at room temperature (until both RAFT agent and initiator were completely dissolved), deoxygenated with nitrogen gas (20 min), and then immersed in a heated oil bath at $70{ }^{\circ} \mathrm{C}$ for $3 \mathrm{~h}$. The flask was then cooled down to room temperature and $8.74 \mathrm{~g}\left(8.39 \times 10^{-2} \mathrm{~mol}\right)$ of Sty was added. The mixture was deoxygenated and reacted for further $5 \mathrm{~h}$ at $70{ }^{\circ} \mathrm{C}$. 

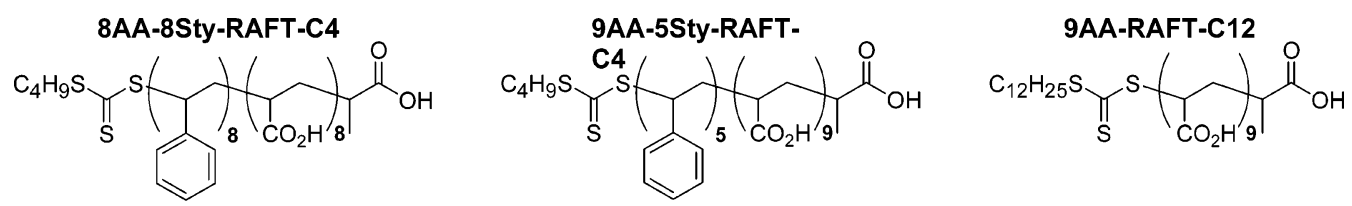

Figure 1. Structure of amphiphilic RAFT-capped mono- and diblocks in order of decreasing hydrophobicity.
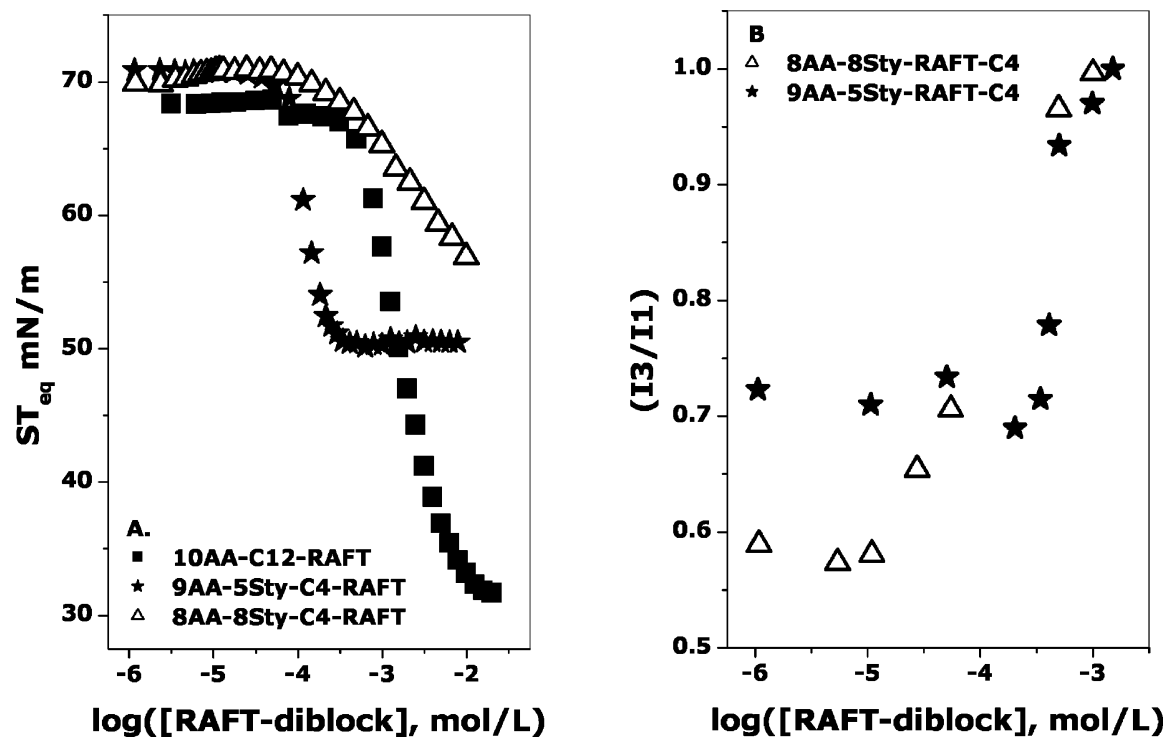

Figure 2. (A) Surface tension, $\gamma$, vs diblock concentrations for 8AA-8Sty-RAFT-C4 (triangles), 9AA-5Sty-RAFT-C4 (stars), and 9AA-RAFTC12 (squares) diblocks. $C m c$ determined from the curves was $7.9 \mathrm{mM}$ for 9AA-RAFT-C12 and $0.23 \mathrm{mM}$ for 9AA-5Sty-RAFT-C4. No cmc could be determined for 8AA-8Sty-RAFT-C4 from $\gamma$ measurements. (B) Variation in the III/I intensity ratio in the emission spectra of pyrene as a function of diblock concentration.

Yellow powder of 8AA-8Sty-RAFT-C4 was obtained after dioxane was removed in a vacuum oven. For the SANS experiments a deuterated diblock (8AA-9Sty- $d_{8}$-RAFT-C4) was prepared using an equimolar amount of Sty- $d_{8}$ to replace the Sty in the above recipe.

Emulsion Polymerization in the Presence of RAFT-Capped Stabilizers. Amphiphilic RAFT-capped mono- or diblock, $\mathrm{NaOH}$, and water were added to a round-bottomed flask and stirred at room temperature (or $40{ }^{\circ} \mathrm{C}$ for the 8AA-8Sty-RAFT-C4) for $30 \mathrm{~min}$ to allow the complete solubilization of the diblocks and micelle formation. A stoichiometric amount of $\mathrm{NaOH}$ was needed to ionize the acid groups of the copolymer since it did not dissolve in water in its acidic form. Initiator, V501, and more $\mathrm{NaOH}$ (sufficient to neutralize the acid groups of the initiator) were added to the flask. The solution was deoxygenated with nitrogen and immersed in an oil bath at $70{ }^{\circ} \mathrm{C}$. A $0.4 \mathrm{~g}$ shot of Sty (equivalent of 30 to 300 Sty units relative to the RAFT) was added to the reaction mix and allowed to react for $1 \mathrm{~h}$. The remaining Sty was then fed at a rate of $1.2 \mathrm{~g} / \mathrm{h}$. The solid content of the emulsions was $\sim 17 \mathrm{wt} \%$. In the case of Sty-BA polymerization BA was added last (after the completion of the Sty feed) at a rate of $3.6 \mathrm{~g} / \mathrm{h}$. The reaction was allowed to continue for another hour after the completion of monomer feed in order to reach high conversion.

\section{Results and Discussion}

Characterization of Diblock Copolymer Micelles. Surface tension and fluorescence were used to determine the critical micelle concentration (cmc) of the three amphiphilic RAFTcapped block copolymers with varying hydrophobicity shown in Figure 1. The critical micelle concentrations of amphiphilic block copolymers are often difficult to determine for various reasons: (i) low diffusion coefficients, sometimes giving rise to kinetically frozen systems; (ii) low $\mathrm{cmc}$, beyond the accessible range of the method; (iii) polydispersity in molecular weight and composition resulting in $\mathrm{cmc}$ stretching over a broad concentration range; (iv) complex tail conformations at the air/ water interface. ${ }^{8}$ Typically the $\mathrm{cmc}$ of polymeric surfactants range from $10^{-9}$ to $10^{-4} \mathrm{~mol} \cdot \mathrm{L}^{-1,19,20}$ while the $\mathrm{cmc}$ of $\mathrm{pAA}-$ pSty block copolymers, with fairly long pAA blocks of 80350 units, have been reported to be in the range $<10^{-5}$ $\mathrm{mol} \cdot \mathrm{L}^{-1} \cdot{ }^{21}$ However, we expected some deviations from the above cmc range due to the relatively low molecular weight and notably shorter pAA block length (only 8-9 AA units) of the RAFT-capped diblocks. This was further supported by the DLS measurements of aqueous 9AA-RAFT-C12 solutions which showed that no micelles were present at concentrations as high as $5 \mathrm{mM}$.

The surface tension of aqueous solutions, $10^{-6}$ to $10^{-2} \mathrm{M}$, of the three amphiphilic RAFT stabilizers was measured using a Du-Nouy ring (See Figure 2), at $22{ }^{\circ} \mathrm{C}$, with 1 (for 9AARAFT-C12) and $30 \mathrm{~min}$ (for the more hydrophobic diblocks) allowed for equilibration between dilutions.

As shown in Figure 2a, typical surfactant behavior was observed for the more hydrophilic 9AA-RAFT-C12 and 9AA5Sty-RAFT-C4. The surface tension, $\gamma$, decreased with concentration then leveled off and became nearly constant at 31.7 and $50.5 \mathrm{mN} / \mathrm{m}$ respectively. These results show that the length of the hydrophobic segment is a key factor controlling the surface activity of the diblocks. Increasing the length of the hydrophobic segment leads to a reduced density of the monolayer at the air/water interface and consequently to an increase in $\gamma$. The cmc for the two diblocks, determined from the intersection of the straight lines of the concentration-dependent and -independent sections, was 7.9 and $0.23 \mathrm{mM}$ respectively. There was no plateau in the surface tension/log(concentration) curve for the 8AA-8Sty-RAFT-C4 diblock in the studied concentration range therefore no $\mathrm{cmc}$ could be determined using this method, despite DLS measurements showing the presence of micelles $\left(D_{\mathrm{H}}=12 \mathrm{~nm}\right)$ at concentrations as low as $10 \mu \mathrm{M}$. One reason could be that considerably slower exchange dynam- 
ics for this diblock, containing $50 \mathrm{~mol} \%$ AA, make it unsuitable for cmc determination using the Du-Nouy ring method. With this method, the air-water interface is constantly renewed due to the movement of the ring and the diffusion equilibrium might not be reached for block copolymers with slow diblock exchange between assemblies.

Pyrene fluorescence measurements were used in order to determine the cmc of 8AA-8Sty-RAFT-C4 (see Figure 2b). It has been shown that variations in the intensity ratio between two of the vibronic bands in the emission spectrum of pyrene (peak I at $\lambda=372.5 \mathrm{~nm}$ and peak III at $\lambda=383.0 \mathrm{~nm}$ ) are strongly influenced by the solvent environment and can be used for cmc determinations. ${ }^{22}$ Solutions with different concentrations of the diblocks in pyrene saturated water were stirred overnight and then measured at room temperature. A sharp increase in the III/I peak ratio was observed at $0.34 \mathrm{mM}$ 9AA-5Sty-RAFT indicative of the solubilization of pyrene in the hydrophobic interior of micelles. This result was in good agreement with the $0.23 \mathrm{mM} \mathrm{cmc}$ determined by surface tension. The increase in the III/I peak intensity ratio occurred over a broad concentration range, $1 \times 10^{-5}$ to $5 \times 10^{-4} \mathrm{~mol} \cdot \mathrm{L}^{-1}$ for the $8 \mathrm{AA}-8 \mathrm{Sty}-$ RAFT-C4 diblock. Micelles were readily observed by DLS over the entire concentration region, therefore the onset of the III/I ratio increase at $10 \mu \mathrm{M} 8 \mathrm{AA}-8$ Sty-RAFT-C4 was determined as the diblock's cmc. The lack of a sharp increase in the ratio of the peaks was attributed to the low $\mathrm{cmc}$ of the diblock. It has been shown that at low surfactant concentrations the partitioning of pyrene between the micelles and the aqueous phase can leave as much as $25-50 \%$ of the pyrene dissolved in the aqueous phase. ${ }^{23}$

Overall, the lability of the diblocks decreased with decreasing cmc with solutions made of the most hydrophobic diblock (8AA-8Sty-RAFT-C4) requiring equilibration times in the range of hours at room temperature. In emulsion polymerization, this reduced mobility will result in an increased stability (on the nucleation time scale) of the more hydrophobic diblock copolymer micelles and a possibility for their direct nucleation in emulsion polymerization.

The aggregation number $\left(N_{\text {agg }}\right)$ of 8AA-8Sty-RAFT-C4 micelles was determined by SANS experiments. A $1 \% \mathrm{v} / \mathrm{v}$ micellar solution of 8AA-9Sty- $d_{8}$-RAFT-C4 was measured in $\mathrm{H}_{2} \mathrm{O}$ at room temperature and $\mathrm{pH}$ 7. The internal labeling of the core allowed good contrast between the core and the shell of the micelles. The data was fitted to the smeared core-shell and structure model supplied by NIST. There are nine fit parameters-core and shell radius, volume fraction, scattering length density (SLD) of the core shell and the solvent, charge, salt concentration, and background. However, many of these can be determined or at least narrowly constrained, by independent means. The best fit to the data corresponded to spherical micelles with a core radius of $3.4 \mathrm{~nm}$, density of $1.04 \mathrm{~g} / \mathrm{mL}$, and a shell thickness of $2.7 \mathrm{~nm}$, corresponding to a fully extended conformation of the oligo-AA tails (see Figure 3). It is then a trivial matter to calculate the micelle aggregation number, $N_{\text {agg }} \cong 90$. The area stabilized by each diblock was determined to be $1.7 \mathrm{~nm}^{2}$.

Effect of Diblock Concentration on the Number of Latex Particles in the Emulsion Polymerization of Sty for RAFTCapped Diblocks with Different Hydrophobicity. In a conventional emulsion polymerization, surfactant molecules migrate freely between micelles, monomer droplets, and the bulk. This exchange also occurs between block copolymer micelles but on a much slower time scale. The time scale of exchange for diblocks of similar nature and molecular weight

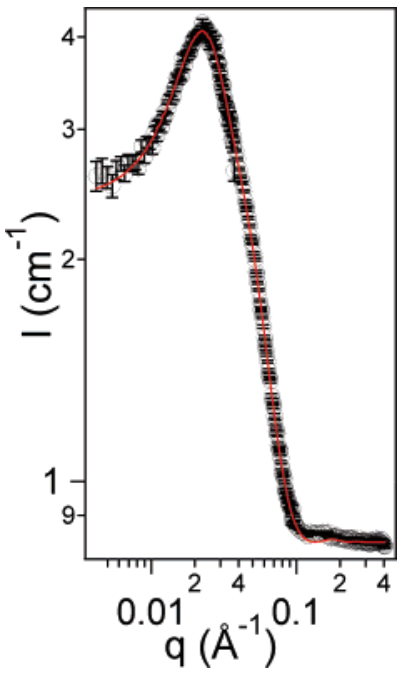

Figure 3. Fit (solid line) to the scattering pattern of fully charged spherical 8AA-9Sty-d8-RAFT-C4 micelles at room temperature and $\mathrm{pH} 7$.

is largely dependent on their overall hydrophobicity. ${ }^{19}$ In this experimental series the three RAFT-capped diblocks (see Figure 1) were used in the emulsion polymerization of Sty or Sty-BA. The concentration of each of the diblocks was varied while the rest of the experimental conditions were kept the same. The range of studied diblock concentrations (from 1 to $5 \mathrm{mM}$ ) was well above the cmc $(\sim 0.01$ and $0.3 \mathrm{mM})$ of the two more hydrophobic diblocks (8AA-8Sty-RAFT-C4 and 9AA-5StyRAFT-C4) and below the cmc for the 9AA-RAFT-C12 Macro RAFT agent. The initiator concentration was $5 \mathrm{mM}$ for all experiments. $N_{\mathrm{p}}$ was calculated from eq 1 and the exponent $\alpha$ (from the Smith and Ewart's power law) was calculated from the gradient of the $\log ([$ stabilizer $])$ vs $\log \left(N_{\mathrm{p}}\right)$ graph. It was expected that for polymerization reactions above the $\mathrm{cmc}$ of the diblocks the exponent $\alpha$ would increase with increasing hydrophobicity of the diblocks and would be close to 1 for the hydrophobic 8AA-8Sty-RAFT-C4. However, as seen in Figure $4 \mathrm{a}$, the exponent $\alpha$ was $\cong 1$ for both diblocks, indicating that RAFT-capped diblock exchange between micelles in the two different systems is slow relative to particle nucleation; i.e., each micelle becomes a particle.

This result was plausible for both 8AA-8Sty-RAFT-C4 and 9AA-5Sty-RAFT-C4 diblocks since the final number of RAFTcapped diblocks per particle $\left(N_{\text {stab }}\right)$ in their latexes, between 110 and 125 for the former, and 180-250 for the latter, was likely to originate from the initial micellar aggregation number (see Table 1). If diblock copolymer micelles can be directly nucleated to become latex particles, $N_{\text {stab }}$ should be independent of the initial diblock concentration and should correspond closely to $N_{\text {agg }}(\sim 90$ diblocks per micelle for 8AA-8Sty-RAFT-C4).

From Table 1 it can be seen that, as expected, $N_{\text {stab }}$ remained relatively constant for different diblock concentrations of 8AA8Sty-RAFT-C4 but was larger by approximately a factor of 1.3 than $N_{\text {agg }}$. This is due to small differences in the average block size and distribution for each of the diblocks (evident in electrospray). The syntheses are not exactly reproducible at the best of times and in addition there are differences in the reactivity of deuterated and non-deuterated monomers.

Also consistent with micelles acting as a seed for particle formation is the trend of increasing area per RAFT-capped chain with decreasing diblock concentration (Figure $4 b$ ). For the same amount of added monomer decreasing the diblock concentration would result in fewer micelles and consequently fewer and larger 

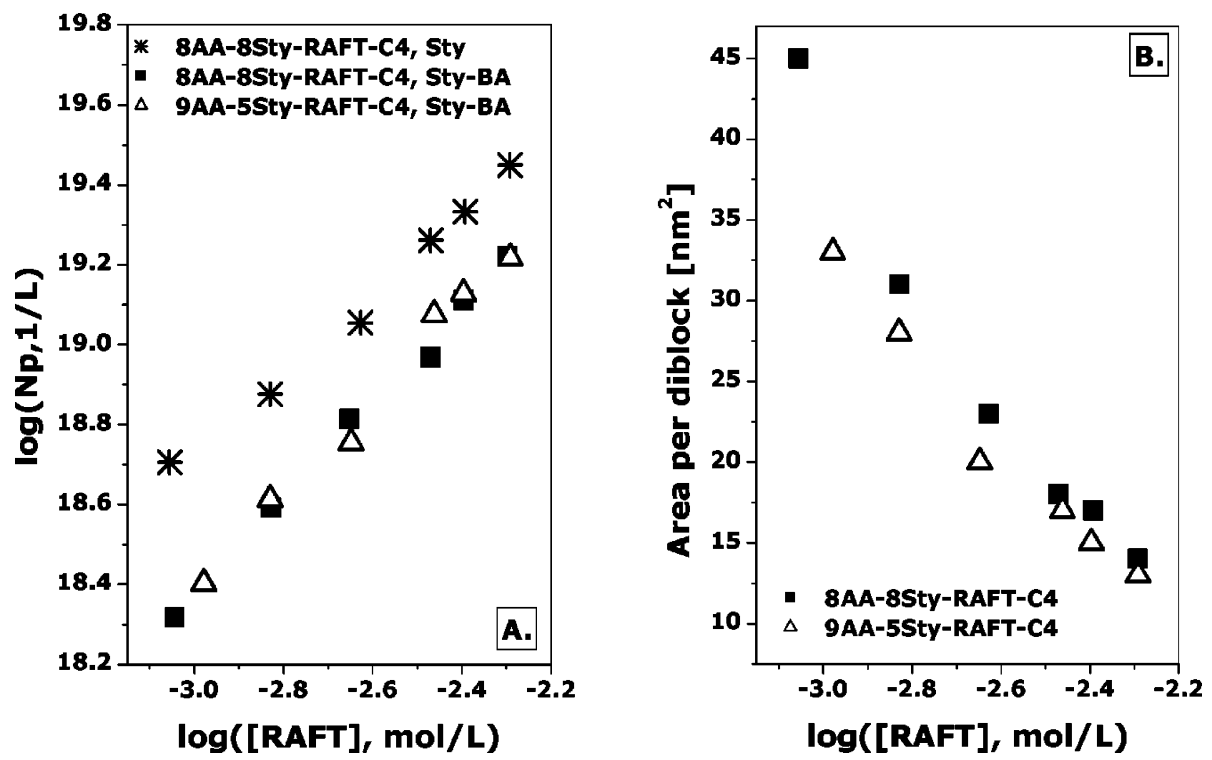

Figure 4. (a) Variation of $N_{\mathrm{p}}$ with stabilizer concentration for RAFT-capped diblocks with different hydrophobicities. The exponent $\alpha$ was 0.90 for the 8AA-8Sty-RAFT-C4, Sty polymerization, stars, 0.98 for 8AA-8Sty-RAFT-C4, Sty-BA polymerization, squares, and 0.99 for the 9AA5Sty-RAFT-C4, Sty-BA polymerization, triangles. (b) Area (in $\mathrm{nm}^{2}$ ) stabilized by RAFT-capped diblocks for different diblock concentrations and hydrophobicities.

Table 1. Surfactant-Free Latexes from the Emulsion Polymerization of Sty, at $70{ }^{\circ} \mathrm{C}$, with $5 \mathrm{mM} \mathrm{V-501}$ and RAFT-Capped Diblock Stabilizers with Varying Hydrophobicity

\begin{tabular}{|c|c|c|c|c|c|c|c|}
\hline stabilizer & $\begin{array}{l}\text { [stab.] } \\
(\mathrm{mM})\end{array}$ & $\begin{array}{l}\text { solids } \\
\left(\mathrm{g} \cdot \mathrm{L}^{-1}\right)\end{array}$ & $\begin{array}{c}D \operatorname{corr}^{a} \\
(\mathrm{~nm})\end{array}$ & $\begin{array}{c}N_{\mathrm{p}} \times 10^{18} \\
\left(\mathrm{~L}^{-1}\right)\end{array}$ & $N_{\text {stab }}{ }^{b}$ & $\begin{array}{c}\text { area stabilized } \\
\text { per RAFT } \\
\text { chain }\left(\mathrm{nm}^{2}\right)\end{array}$ & $N_{\text {stab }} / N_{\text {agg }}$ \\
\hline \multirow[t]{6}{*}{ 8AA-8Sty-RAFT-C4 } & 5.1 & 166 & 22 & 28 & 110 & 14 & 1.2 \\
\hline & 4.1 & 171 & 24 & 21 & 110 & 17 & 1.3 \\
\hline & 3.4 & 165 & 26 & 18 & 110 & 18 & 1.2 \\
\hline & 2.4 & 174 & 30 & 11 & 120 & 23 & 1.4 \\
\hline & 1.5 & 164 & 34 & 7.5 & 120 & 31 & 1.3 \\
\hline & 0.9 & 160 & 39 & 5.1 & 100 & 45 & 1.2 \\
\hline \multirow{6}{*}{ 9AA-5Sty-RAFT-C4 } & 5.1 & 192 & 28 & 17 & 190 & 13 & \\
\hline & 4.0 & 186 & 29 & 13 & 180 & 15 & \\
\hline & 3.5 & 184 & 31 & 12 & 180 & 17 & \\
\hline & 2.3 & 187 & 39 & 5.7 & 240 & 20 & \\
\hline & 1.5 & 190 & 44 & 4.1 & 220 & 28 & \\
\hline & 1.1 & 184 & 51 & 2.5 & 250 & 33 & \\
\hline \multirow[t]{5}{*}{ 9AA-RAFT-C12 } & 6.1 & 156 & 80 & 0.6 & 6600 & 3 & \\
\hline & 5.4 & 140 & 82 & 0.5 & 6900 & 3 & \\
\hline & 4.1 & 148 & 87 & 0.4 & 6000 & 4 & \\
\hline & 3.4 & 141 & 99 & 0.3 & 7500 & 4 & \\
\hline & 1.5 & 156 & 126 & 0.1 & 6500 & 8 & \\
\hline
\end{tabular}

${ }^{a} \mathrm{D}(\mathrm{HDC})$ corr $=$ HDC diameter corrected by subtracting the shell thickness determined by SANS. The correction was done for all three diblocks since the length of the hydrophilic block is relatively constant $\sim 8-9$ AA units. ${ }^{b} N_{\text {stab }}=$ number of RAFT-capped diblocks per particle

particles. Since there should be no RAFT-capped diblock exchange between micelles the bigger the particle the larger the area stabilized by a RAFT-capped chain.

The latexes formed below the cmc of the 9AA-RAFT-C12 Macro RAFT had a significantly larger particle diameter, 80$126 \mathrm{~nm}$ (see Table 1), and denser surface coverage $\left(\sim 3-4 \mathrm{~nm}^{2}\right.$ stabilized by a RAFT chain). The surface coverage remained relatively constant with stabilizer concentration indicative of the different mechanism operating in this case, not only due to the lack of micelles in the system but also due to the higher mobility of the Macro RAFT in comparison to the 8AA-8StyRAFT-C4 and9AA-5Sty-RAFT-C4 diblocks.

SEC measurements were carried out on samples taken during a Sty-BA polymerization which employed a 8AA-8Sty-RAFTC4 stabilizer, $5.2 \mathrm{mM}$ V501 and $3.5 \mathrm{mM}$ RAFT agent. It can be seen in Figure 5 that a linear increase of $M_{\mathrm{n}}$ with the amount of monomer fed was observed.

The use of universal calibration with polySty/polyBA MarkHouwink parameters for polymer with pAA block end groups is questionable and may lead to misleading values both for $M_{\mathrm{n}}$ and PDI. ${ }^{5}$ Hence, the results in Figure 5 should simply be used as a qualitative demonstration of the livingness of the system. Moreover, the initiator concentrations used in this run was very high and would be expected to lead to a considerable amount of termination, with a consequent reduction in $M_{\mathrm{n}}$.

Effect of Initiator Concentration. In the limiting case where $\alpha \cong 1$ and each micelle becomes a particle, initiator concentration should not considerably affect the final number of latex particles. The micelles of the RAFT-capped diblocks should be "frozen" on the time scale of nucleation. Further growth of the hydrophobic block would render the diblocks incapable of desorbing from the micelles on any time scale. A series of experiments varying the initiator concentration while keeping the RAFT-capped diblock concentration constant at $2.5 \mathrm{mM}$ was carried out (see Figure 6 and Table 2).

A linear increase of $N_{\mathrm{p}}$ with increasing initiator concentration was observed for 8AA-8Sty-RAFT-C4 and 9AA-5Sty-RAFT$\mathrm{C} 4$, after which a plateau was reached. This trend was consistent 


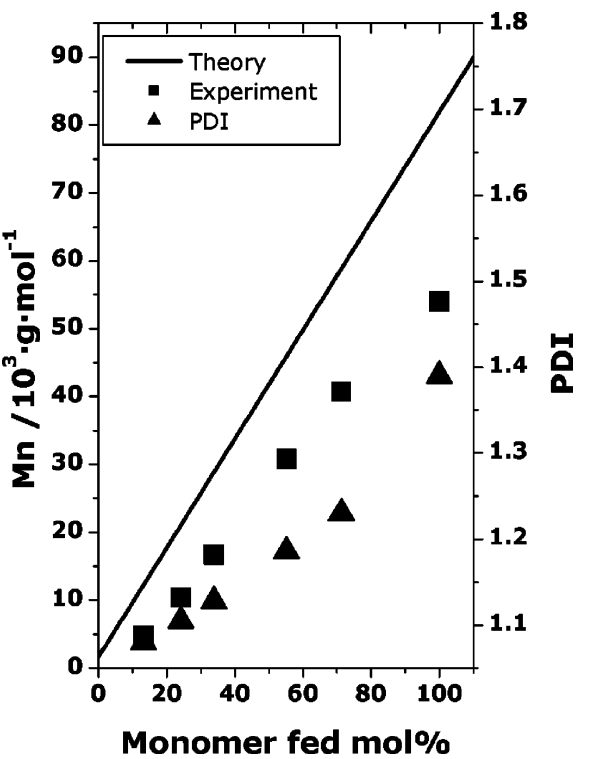

Figure 5. Average $M_{\mathrm{n}}$ (relative to polystyrene standards and using universal calibration) as a function of monomer content.

Scheme 2. Basic Steps in the Suggested Mechanism for Particle Formation in Emulsion Polymerization Stabilized by Amphiphilic RAFT-Capped Diblocks Present in Concentrations above Their $\mathrm{Cmc}^{a}$

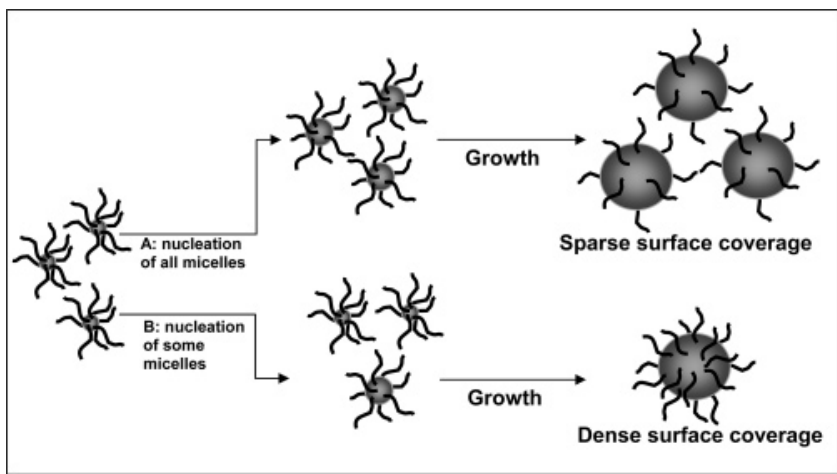

${ }^{a}$ Route A: micelles act as a seed. Route B: some micelles are nucleated and others serve as a diblock reservoir.

with a mechanism where at low initiator concentrations, z-mers enter some but not all of the micelles, which then grow further to become the latex particles. As the nucleated micelles grow, RAFT-capped diblocks from unentered micelles transport through the aqueous phase to stabilize the newly formed surface area. With increasing initiator concentration more micelles are entered until a limit is reached where enough radicals to enter each micelle are generated on the time scale of micelle lifetime and a plateau in Figure $6 \mathrm{a}$ is observed.

The onset of the plateau (in Figure 6a) occurred at lower initiator concentration $\sim 3 \mathrm{mM}$ for the more hydrophobic diblock, 8AA-8Sty-RAFT-C4. This was consistent with our surface tension results that showed that the more hydrophobic the diblock the slower the exchange of RAFT-capped diblocks between assemblies and the longer the lifetime of the micelles. Micelles would appear as "frozen" for a longer period of time, allowing for more radicals to be generated in that time interval. Therefore, lower initiator concentrations would be able to generate a sufficient radical flux to enter all of the micelles of the more hydrophobic 8AA-8Sty-RAFT-C4. From Figure 6a, it was clear that a $5 \mathrm{mM}$ initiator concentration would be sufficient to enter all micelles in both the 8AA-8Sty-RAFT-C4 and 9AA-5Sty-RAFT-C4 systems, which explains why $\alpha \cong 1$ for both diblocks in Figure 4a. Knowing the micelle concentra- tion (from the concentration and the $N_{\mathrm{agg}}, \sim 90$, of 8AA-8StyRAFT-C4 diblock) and the initiator concentration and decomposition rate at $\left(k_{\mathrm{d}}=2.3 \times 10^{-5} \mathrm{~s}^{-1}\right.$ for V501 at $\left.70{ }^{\circ} \mathrm{C}\right)$ we can calculate the micelle lifetime from the onset of the plateau in Figure 6a. Thus, assuming 100\% initiator efficiency, a minimum of $200 \mathrm{~s}$ micelle lifetime is required for all 8AA8Sty-RAFT-C4 micelles to be nucleated.

The above results differ significantly from the work of Burguière et al. ${ }^{10}$ where there was no dependence of $N_{\mathrm{p}}$ on [I] due to the significantly longer AA hairs (50-300 AA units per diblock) of the stabilizing diblocks. It was proposed that in those systems the rate of radical entry through the dense neutralized AA shell and not the rate of radical generation was rate determining for the particle nucleation step.

The initiator concentration dependence in the 9AA-RAFTC12 system (Figure 6b) was indicative of a different particle formation mechanism operating below the cmc of this (most hydrophilic of the three) diblocks.

There could be two possible nucleation mechanisms in a system below the cmc of the RAFT-capped stabilizer. The first one involves the stabilizer growing a hydrophobic tail in the aqueous phase until it is capable of assembly similarly to the mechanism proposed originally by Ferguson et al. ${ }^{5}$ However, recent results by Nguyen et al. ${ }^{24}$ have shown that RAFT-C4capped random copolymers, incapable of self-assembly into aggregates, do not grow competitively in the water phase but only if adsorbed into more hydrophobic surroundings. The only remaining option for nucleation below the cmc of the RAFTcapped stabilizer is the homogeneous-coagulative nucleation mechanism..$^{25,26}$ In this mechanism, precursor particles are formed when primary initiator radicals react with monomer (in this case Sty) in the aqueous phase and grow beyond a critical degree of polymerization $j_{\text {crit }}$. Such precursor particles then swell with monomer and are rapidly stabilized by the amphiphilic RAFT-capped stabilizer. Polymerization then continues under RAFT control in the particle. The rate of production of oligomers that reach the critical length $j_{\text {crit }}\left(j_{\text {crit }}=5 \text { for Sty }\right)^{27}$ is then the upper limit for the rate of formation of particles and can be described with eq $2 .^{28}$

$$
j_{\text {crit }}-\text { mers }\left(\mathrm{dm}^{-3} \mathrm{~s}^{-1}\right)=2 k_{\mathrm{d}}[\mathrm{I}] N_{\mathrm{A}}\left\{\frac{\left(k_{\mathrm{d}}[\mathrm{I}] k_{\mathrm{t}, \mathrm{aq}}\right)^{0.5}}{k_{\mathrm{p}, \mathrm{aq}} C_{\mathrm{w}}}+1\right\}^{1-j \text { crit }}
$$

where $k_{\mathrm{d}}$ is the rate of initiator decomposition $\left(k_{\mathrm{d}}=2.3 \times 10^{-5}\right.$ $\mathrm{s}^{-1}$ for $\mathrm{V} 501$ at $\left.70{ }^{\circ} \mathrm{C}\right), k_{\mathrm{t}, \mathrm{aq}}$ is the rate of aqueous phase termination $\left(k_{\mathrm{t}, \mathrm{aq}}=1.75 \times 10^{9} \mathrm{dm}^{3} \cdot \mathrm{mol}^{-1} \cdot \mathrm{s}^{-1}\right.$ for Sty at $\left.70{ }^{\circ} \mathrm{C}\right), k_{\mathrm{p}, \text { aq }}$ is the rate of aqueous phase propagation $\left(k_{\mathrm{p}, \mathrm{aq}}=\right.$ $\left.480 \mathrm{dm}^{3} \cdot \mathrm{mol}^{-1} \cdot \mathrm{s}^{-1}\right),[\mathrm{I}]$ and $C_{\mathrm{W}}\left(5.6 \times 10^{-3} \mathrm{M} \text {, Sty at } 70{ }^{\circ} \mathrm{C}\right)^{29}$ are the initiator concentration and monomer concentration in the aqueous phase respectively. Applying eq 2 to the 9AARAFT-C12 system below its cmc, it can be seen that increasing [I] over the range range 0.6 to $10.2 \mathrm{mM}$ actually decreases the rate of production of $j_{\text {crit }}$-mers. This is due to increased termination in the aqueous phase. The number of $j_{\text {crit }}$-mers predicted to form in $30 \mathrm{~min}$ over this range of initiator concentrations is in remarkable agreement with the number of particles observed experimentally (see Figure 7). These results suggest that particle nucleation in the 9AA-RAFT-C12 system proceeds by a pure homogeneous nucleation mechanism rather than the hybrid homogeneous nucleation/coagulation mechanism that is usually encountered in conventional emulsion polymerization systems operating below the surfactant cmc. Here, the remarkable ability of these macro-RAFT surfactants to stabilize 

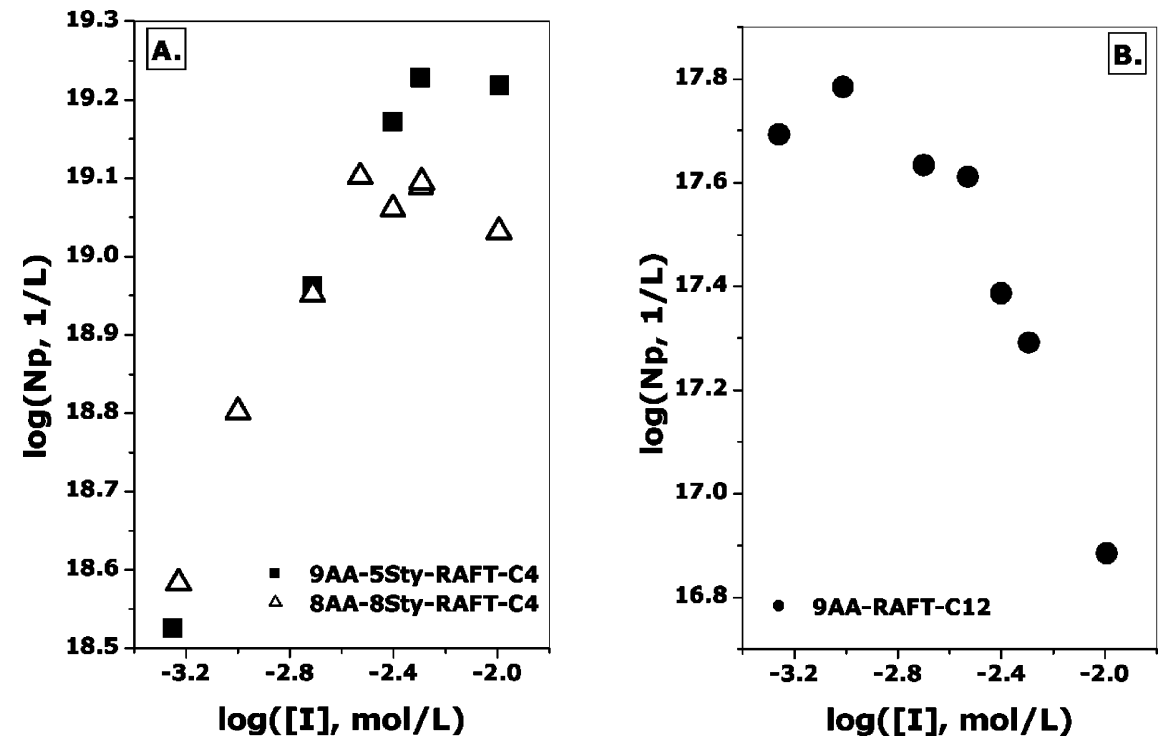

Figure 6. Initiator concentration dependence of particle number for polystyrene emulsions (A) above the cmc of the stabilizers, 8AA-8Sty-RAFTC4 (black squares) and 9AA-5Sty-RAFT-C4 (triangles), and (B) below the cmc of the stabilizing 9AA-RAFT-C12 Macro RAFT agent.

Table 2. Surfactant-Free Latexes from the Emulsion Polymerization of Sty, at $70{ }^{\circ} \mathrm{C}$, with Constant 2.5 or 3.3 mM Diblock Concentration and Varying Amounts of Initiator

\begin{tabular}{|c|c|c|c|c|c|c|}
\hline stabilizer & $\begin{array}{c}\text { [initiator] } \\
(\mathrm{mM})\end{array}$ & $\begin{array}{c}\text { solids } \\
\left(\mathrm{g} \cdot \mathrm{L}^{-1}\right)\end{array}$ & $\begin{array}{c}D(\mathrm{HDC}) \\
\operatorname{corr}^{a}(\mathrm{~nm}) \\
\end{array}$ & $\begin{array}{c}N_{\mathrm{p}} \times 10^{18} \\
\left(\mathrm{~L}^{-1}\right)\end{array}$ & $N_{\text {stab }}$ & $\begin{array}{c}\text { area stabilized } \\
\text { per RAFT } \\
\text { chain }\left(\mathrm{nm}^{2}\right)\end{array}$ \\
\hline \multirow{7}{*}{ 8AA-8Sty-RAFT-C4 } & 10.1 & 166 & 30 & 11 & 140 & 21 \\
\hline & 5.1 & 177 & 30 & 12 & 120 & 23 \\
\hline & 4.0 & 165 & 30 & 12 & 130 & 21 \\
\hline & 3.0 & 145 & 28 & 13 & 120 & 20 \\
\hline & 1.9 & 176 & 33 & 9 & 170 & 20 \\
\hline & 1.0 & 161 & 36 & 6 & 240 & 17 \\
\hline & 0.6 & 159 & 42 & 4 & 390 & 14 \\
\hline \multirow{5}{*}{ 9AA-5Sty-RAFT-C4 } & 10.2 & 159 & 26 & 17 & 120 & 17 \\
\hline & 5.1 & 157 & 26 & 17 & 120 & 17 \\
\hline & 4.0 & 163 & 27 & 15 & 140 & 17 \\
\hline & 1.9 & 166 & 32 & 9 & 220 & 15 \\
\hline & 0.6 & 152 & 44 & 3 & 600 & 10 \\
\hline \multirow[t]{7}{*}{ 9AA-RAFT-C12 } & 10.2 & 162 & 157 & 0.1 & 20000 & 4 \\
\hline & 5.1 & 160 & 114 & 0.2 & 7700 & 5 \\
\hline & 4.0 & 149 & 104 & 0.2 & 6200 & 5 \\
\hline & 3.0 & 167 & 91 & 0.4 & 3700 & 7 \\
\hline & 2.0 & 149 & 86 & 0.4 & 3500 & 7 \\
\hline & 1.0 & 147 & 76 & 0.6 & 2500 & 7 \\
\hline & 0.6 & 144 & 81 & 0.5 & 3000 & 7 \\
\hline
\end{tabular}

${ }^{a} \mathrm{D}(\mathrm{HDC})$ corr $=$ HDC diameter corrected by subtracting the shell thickness determined by SANS. The correction was done for all three diblocks since the length of the hydrophilic block is relatively constant $\sim 8-9$ AA units.

large particle surface areas, would appear to allow each $j_{\text {crit }}{ }^{-}$ mer to become stabilized as a particle.

Effect of Diblock Hydrophobicity at Low Initiator Concentration. On the basis of the initiator concentration dependence of $N_{\mathrm{p}}$ (Figure 6a), it was likely that at [I] lower than $3 \mathrm{mM}$ (where insufficient radical flux was generated during the micelle lifetime) there would be a noticeable variation in the values of the exponent $\alpha$ for the diblocks with different hydrophobicity. The change in $\alpha$ was expected to be more pronounced for the more hydrophilic (and therefore more labile) 9AA-5Sty-RAFT-C4 diblock. For this series of experiments the initiator concentration was kept constant at $2 \mathrm{mM}$ and the diblock concentration was varied from 1 to $5 \mathrm{mM}$ (see Figure 8). The 9AA-RAFT-C12 macro-RAFT, was not included in this experimental series as it does not form micelles in the studied concentration range.

From Figure $8 \mathrm{a}$, it can be seen that at $2 \mathrm{mM}[\mathrm{I}]$, the more hydrophilic 9AA-5Sty-RAFT-C4 diblock gives an exponent $\alpha$ $=0.61$, typical of that of low molecular weight surfactants in the emulsion polymerization of Sty. ${ }^{13}$ As expected, the value

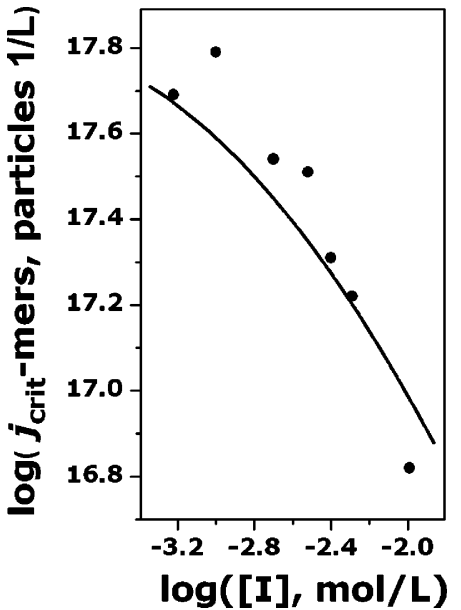

Figure 7. Solid line: Cumulative number of $j_{\text {crit }}$-mers predicted by eq 2 after $30 \mathrm{~min}$ for a styrene polymerization with V501 initiator at $70{ }^{\circ} \mathrm{C}$. Solid circles: number of particles observed under the same conditions. 

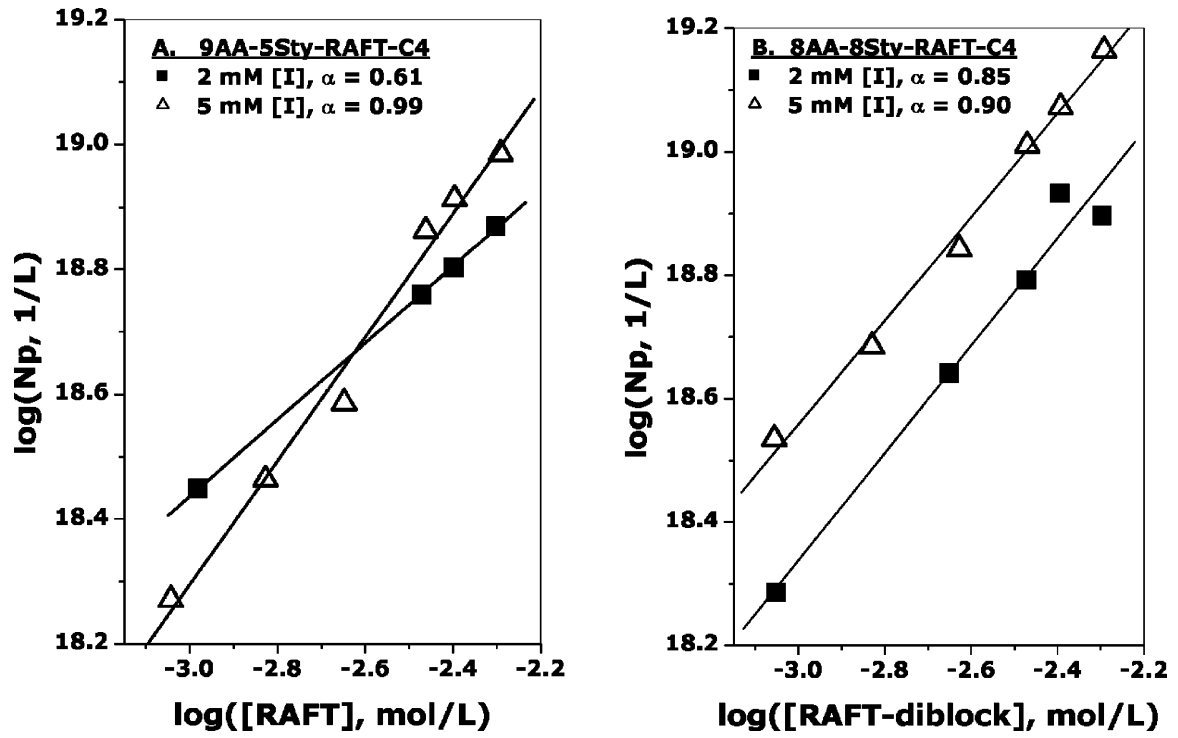

Figure 8. Plots of $N_{\mathrm{p}}$ vs diblock concentration at 2 and $5 \mathrm{mM}$ initiator concentrations for (A) 9AA-5Sty-RAFT-C4 diblock, and (B) 8AA-8StyRAFT-C4 diblock.

Table 3. Variation of Monomer Feed Conditions ${ }^{a}$

\begin{tabular}{|c|c|c|c|c|}
\hline reaction & feed conditions & $\begin{array}{c}\text { particle } \\
\text { diameter }^{30}\end{array}$ & $\begin{array}{c}N_{\mathrm{p}} \times 10^{18} \\
\left(\mathrm{~L}^{-1}\right)\end{array}$ & $\begin{array}{l}\text { no. of RAFT } \\
\text { molecules per } \\
\text { particle }\end{array}$ \\
\hline 1 & benchmark procedure: slow Sty feed, followed by fast Sty feed & 33.7 & 7.66 & 176 \\
\hline 2 & shot of 30 Sty units is reacted for $1 \mathrm{~h}$ followed by fast Sty feed & 35.8 & 6.96 & 204 \\
\hline 3 & fast Sty feed throughout the reaction & 36.7 & 6.04 & 223 \\
\hline 4 & batch reaction & 46.3 & 3.22 & 384 \\
\hline
\end{tabular}

${ }^{a}$ For experiments 1, 2, and 3, a solution of RAFT-capped diblock, V-501 Initiator, and $\mathrm{NaOH}$ in water was prepared. The solution was deoxygenated with $\mathrm{N}_{2}$ and immersed in an oil bath at $70{ }^{\circ} \mathrm{C}$ and monomer addition begun. For experiment 4 , the entire amount of Sty was added to the above solution and stirred at room temperature for $30 \mathrm{~min}$. The emulsion was then flushed with $\mathrm{N}_{2}$ and the flask was placed into an oil bath at $70{ }^{\circ} \mathrm{C}$.

of the exponent $\alpha$ for 8AA-8Sty-RAFT-C4 (Figure 8b) remained close to 1 both at 2 and $5 \mathrm{mM}[\mathrm{I}]$, suggesting that most of the micelles in this system are stable enough to be nucleated. This is due to the greater hydrophobicity of the diblock (50 mol \% AA compared to $67 \mathrm{~mol} \%$ for 9AA-5Sty-RAFT-C4) and the expected much slower RAFT-capped diblock exchange dynamics.

Effect of Monomer Feed on $\boldsymbol{N}_{\mathrm{p}}$. In previous work on the system, it was postulated that it is important to avoid droplet formation in the initial stages of the reaction until all RAFTcapped chains had become sufficiently hydrophobic and unable to desorb from the particles. ${ }^{7}$ This was based on the assumption that both Macro-RAFT agent and RAFT-capped diblocks are capable of stabilizing monomer droplets due to their exchange through the water phase.

On the basis of our current result that the breaking of the micelles of RAFT-capped diblocks is slow with respect to the nucleation process, the rate of monomer addition should no longer present a risk for droplet nucleation. If micelles are rigid during the particle nucleation step there should be no migration of RAFT-capped diblocks. However, the presence of monomer may have an effect on micelle size and aggregation number.

A series of experiments were performed where the effect of monomer feed on the final number of latex particles for a 8AA8Sty-RAFT-C4 stabilized system was investigated. Results of different monomer feed experiments were compared to the benchmark slow initial feed experiment of Ferguson et al. ${ }^{5}$ (see Table 3).

As expected there was not a pronounced difference in the results of experiments 1 and 2. The shot addition of 30 Sty units relative to moles of RAFT-capped diblock is equivalent to a Sty concentration of $15.1 \mathrm{~g} / \mathrm{L}$. This concentration is significantly above the Sty solubility in water at $70^{\circ} \mathrm{C}$ of $\sim 0.6$ $\mathrm{g} / \mathrm{L}$. The fast feed $(1.4 \mathrm{~mL} / \mathrm{h})$ of Sty throughout the entire reaction (experiment 3) gave only a slight increase in both particle diameter and number of RAFT-capped diblocks per particle, possibly due to some rearrangement in the micelle structure caused by the larger excess of Sty prior to nucleation. In the batch experiment (4), where the entire amount of Sty was emulsified with the diblock and water for $30 \mathrm{~min}$ prior to the polymerization, that rearrangement is considerable, leading to a substantial decrease in $N_{\mathrm{p}}$.

Revised Nucleation Mechanism in an Emulsion Polymerization Stabilized by Amphiphilic RAFT-Capped Diblocks above Their Cmc. On the basis of all of the above results, the mechanism of particle nucleation in the system can be summarized by the following scheme (Scheme 2).

Route A in Scheme 2 is characteristic of diblocks with low ( $\sim 50 \mathrm{~mol} \%$ ) and medium (between 60 and $70 \mathrm{~mol} \%$ ) AA content combined with high initiator concentration for the latter. The high initiator concentration for the relatively labile, medium AA content RAFT-capped diblock micelles, allows the nucleation of all micelles by the generation of more radicals in a shorter time interval. Route B is characteristic of diblocks with intermediate AA content (between 60 and $70 \mathrm{~mol} \%$ ) at low initiator concentrations or high AA content at any initiator concentration. It can be seen that the mechanism of particle formation in this system is rather versatile as it can be tuned not only by changing the diblock hydrophobicity (which requires the chemical synthesis of a variety of diblocks) but also by simply changing initiator concentration to achieve the desired effect. Diblocks with intermediate hydrophobicity (containing 
between 60 and $70 \mathrm{~mol} \% \mathrm{AA}$ ) are best to use in emulsion polymerization since they dissolve readily in water at room temperature and behave in a similar way to low molecular weight surfactants at low initiator concentrations, and their micelles can act as seed particles at high initiator concentrations.

\section{Conclusions}

Amphiphilic $\mathrm{AA}_{x} \mathrm{Sty}_{y}$ RAFT-capped diblocks with varying hydrophobicity $(x=8,9 ; y=8,5,0)$ were employed as stabilizers in the emulsion polymerization of Sty. The lability of the diblocks was found to be largely dependent on their overall hydrophobicity, resulting in equilibration times (at room temperature) in the range from seconds to hours. Under the emulsion polymerization conditions all diblocks were labile and capable of exchanging RAFT-capped diblocks through the aqueous phase. This rate of exchange was on a similar time scale to that of particle nucleation. The nucleation of all micelles was therefore possible, providing sufficient amount of initiator radicals are generated on the time scale of micelle lifetime. For systems stabilized with the most hydrophobic (least labile) 8AA8Sty-RAFT-C4 diblock, initiator concentrations $>3 \mathrm{mM}$ were sufficient to nucleate all micelles. For the less hydrophobic (more labile) 9AA-5Sty-RAFT-C4 diblock initiator concentrations $>5 \mathrm{mM}$ were required. More radicals can be generated during the longer lifetime of the less labile 8AA-8Sty-RAFTC4 micelles allowing $3 \mathrm{mM}$ V501 to generate sufficient flux of radicals. Since there was no additional stabilizer in the system, as particles grow each oligo-acrylic acid chain has to stabilize an area of $10-40 \mathrm{~nm}^{2}$. At low initiator concentrations only some of the micelles could be nucleated and grow while unentered micelles served a reservoirs (break up, migrate to stabilize newly created particle surface and grow until they are too hydrophobic to desorb). A homogeneous nucleation mechanism is most likely to operate below the $\mathrm{cmc}$ of the diblocks.

Acknowledgment. This work utilized facilities supported in part by the National Science Foundation under Agreement No. DMR-0454672. The authors acknowledge the support of the National Institute of Standards and Technology, U.S. Department of Commerce, in providing the neutron research facilities used in this work. Financial support for the project was provided by Dulux Australia and the Australian Research council. Hollie Zondanos is thanked for the assistance with the SEC.

\section{References and Notes}

(1) Moad, G.; Rizzardo, E.; Thang, S. H. Aust. J. Chem. 2005, 58, 379410.

(2) Uzulina, I.; Kanagasabapathy, S.; Claverie, J. Macromol. Symp. 2000 $150,33-38$.
(3) Moad, G.; Chiefari, J.; Chong, Y. K.; Krstina, J.; Mayadunne, R. T. A.; Postma, A.; Rizzardo, E.; Thang, S. H. Polym. Int. 2000, 49, $993-$ 1001.

(4) Ferguson, C. J.; Hughes, R. J.; Pham, B. T. T.; Hawkett, B. S.; Gilbert, R. G.; Serelis, A. K.; Such, C. H. Macromolecules 2002, 35, 92439245.

(5) Ferguson, C. J.; Hughes, R. J.; Nguyen, D.; Pham, B. T. T.; Gilbert, R. G.; Serelis, A. K.; Such, C. H.; Hawkett, B. S. Macromolecules 2005, 38, 2191-2204.

(6) Gilbert, R. G. Macromolecules 2006, 39, 4256-4258.

(7) Sprong, E.; Leswin, J. S. K.; Lamb, D. J.; Ferguson, C. J.; Hawkett, B. S.; Pham, B. T. T.; Nguyen, D.; Such, C. H.; Serelis, A. K.; Gilbert, R. G. Macromol. Symp. 2006, 231, 84-93.

(8) Zana, R. Dynamics of Surfactant Self-Assemblies: Micelles, Microemulsions, Vesicles, and Lyotropic Phases. Surf. Sci. Ser. 2005, 125, 518.

(9) Rager, T.; Meyer, W. H.; Wegner, G.; Mathauer, K.; Machtle, W.; Schrof, W.; Urban, D. Macromol. Chem. Phys. 1999, 200, 16811691.

(10) Burguière, C.; Pascual, S.; Bui, C.; Vairon, J.-P.; Charleux, B.; Davis, K. A.; Matyjaszewski, K.; Betremieux, I. Macromolecules 2001, 34, $4439-4450$.

(11) Burguière, C.; Chassenieux, C.; Charleux, B. Polymer 2003, 44, 509518.

(12) Smith, W. V.; Ewart, R. H. J. Chem. Phys. 1948, 16, 592-599.

(13) Sütterlin, N. Influence of monomer polarity on particle formation in emulsion polymerization. In Polymer Colloids II; Fitch, R. M., Ed. Plenum: New York, 1980; pp 583-597.

(14) van Stam, J.; Creutz, S.; De Schryver, F. C.; Jerome, R. Macromolecules 2000, 33, 6388-6395.

(15) Glinka, C. J.; Barker, J. G.; Hammouda, B.; Krueger, S.; Moyer, J. J.; Orts, W. J. J. Appl. Crystallogr. 1998, 31, 430-445.

(16) Kline, S. R. J. Appl. Crystallogr. 2006, 39, 895-900.

(17) Mori, S.; Barth, H. G. Size Exclusion Chromatography; Springer: Berlin, 1999.

(18) Hutchinson, R. A.; Paquet, D. A.; McMinn, J. H.; Beuermann, S.; Fuller, R. E.; Jackson, C. DECHEMA Monogr. 1995, 131, 467.

(19) Creutz, S.; van Stam, J.; De Schryver, F. C.; Jerome, R. Macromolecules 1998, 31, 681-689.

(20) Garnier, S.; Laschewsky, A. Langmuir 2006, 22, 4044-4053.

(21) Khougaz, K.; Astafieva, I.; Eisenberg, A. Macromolecules 1995, 28, $7135-7147$.

(22) Kalyanasundaram, K.; Thomas, J. K. J. Am. Chem. Soc. 1977, 99 , 2039-2044

(23) Stepanek, M.; Krijtova, K.; Prochazka, K.; Teng, Y.; Webber, S. E.; Munk, P. Acta Polym. 1998, 49 (2-3), 96-102.

(24) Nguyen, D.; Key Centre for Polymer Collids, F11 University of Sydney, NSW 2006, Australia, Private correspondence.

(25) Fitch, R. M.; Tsai, C. H. Particle formation in polymer colloids. III Prediction of the number of particles by a homogeneous nucleation theory. In Polymer Colloids; Fitch, R. M., Ed.; Plenum: New York, 1971; pp 73-102.

(26) Ugelstad, J.; Hansen, F. K. Rubber Chem. Technol. 1976, 49, 536609.

(27) Gilbert, R. G. Emulsion Polymerization: A Mechanistic Approach; London, 1995; p 384.

(28) Casey, B. S.; Morrison, B. R.; Gilbert, R. G. Prog. Polym. Sci. 1993, $18,1041-1096$.

(29) Lane, W. H. Ind. Eng. Chem., Anal. Ed. 1946, 18, 295-296.

(30) Tian, M.; Qin, A.; Ramireddy, C.; Webber, S. E.; Munk, P.; Tuzar, Z.; Prochazka, K. Langmuir 1993, 9, 1741-1748. 